\title{
APLIKASI PENGADUAN MASYARAKAT UNTUK MELAPORKAN KEJADIAN PUNGUTAN LIAR DI KABUPATEN KUDUS BERBASIS ANDROID
}

\author{
Arsya Yoga Pratama \\ Fakultas Teknik, Program Studi Sistem Informasi \\ Universitas Muria Kudus \\ Email:201553011@std.umk.ac.id \\ Iman Ardhi Prabowo \\ Fakultas Teknik, Program Studi Sistem Informasi \\ Universitas Muria Kudus \\ Email:201553013@std.umk.ac.id \\ Alifah Normassari \\ Fakultas Hukum, Program Studi Ilmu Hukum \\ Universitas Muria Kudus \\ Email: Aliva.normass@gmail.com
}

\begin{abstract}
ABSTRAK
Jurnal ini merupakan publikasi dari program kreativitas mahasiswa bidang karsa cipta yang telah dilakukan yang berhubungan dengan pelaporan pungutan liar. Program tersebut sebagai upaya membantu pemerintah untuk mengurangi terjadinya pungutan liar (Pungli) khususnya di Kabupaten Kudus dan mengoptimalkan kinerja tim saber pungli. Hasil dari perancangan ini adalah Sistem Informasi yang menyajikan hasil analisa dan rancangan yang dituangkan dalam diagram UML (Unified Modeling Language) yang terdiri dari Use Case dan Activity Diagram. Didalam jurnal ini akan menyarankan utuk dapat membuat sebuah sistem yang dapat mempermudah dalam melaporkan kejadian pemungutan liar. Hasil dari penelitian ini merupakan salah satu solusi yang dapat digunakan dalam menangani permasalahan di Kabupaten Kudus dengan membuat aplikasi ALPUKAT, ALPUKAT adalah suatu sistem aplikasi pengaduan masayarakat berbasis Android yang berfungsi untuk melaporkan terjadinya pungutan liar di kabupaten kudus .Keunggulan aplikasi ini sudah menggunakan teknologi GIS (Geographic Information System).
\end{abstract}

Kata kunci: Pungli, ALPUKAT, Android, UML, GIS.

\begin{abstract}
This journal is a publication of the creativity program of students in the field of copyright that has been done related to the reporting of illegal levies. The program is an effort to help the government to reduce the occurrence of illegal levies (pungli) charges in the Kudus and Optimize performance team Saber pungli. The results of this design are the Information System that presents the results of analysis and design as outlined in the diagram UML (Unified Modeling Language) consisting of Use Case and Activity Diagram. In this journal, it will be suggested to create a system that can facilitate the reporting of illegal harvesting events. The results of this research are one solution that can be used in handling problems in Kabupaten Kudus by creating applications ALPUKAT. ALPUKAT is system aplication public complent based android that can be used report do Illegal charges in the Kudus .Excellence applications produced on the basis of GIS (Geographic Information System).
\end{abstract}

Keywords: Pungli, ALPUKAT, Android, UML, GIS.

\section{PENDAHULUAN}

Pungutan liar merupakan perbuatan-perbuatan yang disebut sebagai perbuatan pungli merupakan suatu gejala sosial yang telah ada di Indonesia, sejak Indonesia masih dalam masa penjajahan dan bahkan jauh sebelum itu. Pemerintah Indonesia juga pada akhir-akhir ini tengah gencar-gencarnya memberantas pungutan liar. Pemerintah saat ini sudah membentuk tim saber pungli berdasarkan Perpres Nomor 87/2016 tentang Satuan Tugas Sapu Bersih yang mempunyai tugas melaksanakan pemberantasan pungutan liar secara efektif dan efisien dengan mengoptimalkan pemanfaatan personil, satuan kerja, dan sarana prasarana, baik yang berada di kementerian/lembaga maupun pemerintah daerah [1]. Ditengah 
globalisasi saat ini dengan berbagai macam teknologi yang sangat pesat banyak sekali terciptanya alatalat untuk membantu masyarakat menyelesaikan persoalan dengan mudah. Salah satu teknologi untuk membantu masayarakat dalam menemukan lokasi adalah GPS. GPS (Global Positioning System) adalah sistem untuk menentukan posisi dan navigasi secara global dengan menggunakan satelit. GPS dapat memberikan informasi tentang posisi, kecepatan, dan waktu secara cepat, akurat, murah, dimana saja bumi ini pada setiap saat tanpa tergantung cuaca [2]. Teknologi GPS saat ini sudah ada di dalam fitur yang terdapat pada gadget smartphone android. Teknologi GPS biasa digunakan untuk menentukan lokasi dengan akurat.

Dengan adanya kekurangan pada sistem yang dibuat oleh pemerintah dan dengan adanya teknologi GPS yang terdapat pada teknologi android, TIM PKM KC ingin mengaplikasikan teknologi tersebut untuk membuat sistem pelaporan pungutan liar berbasiskan android dengan menggunakan teknologi GPS untuk menentukan lokasi kegiatan pungutan liar. Manfaat yang diperoleh adanya sistem ini adalah masyarakat atau pengguna sistem dapat dengan mudah melaporkan kegiatan pungutan liar dengan keakuratan lokasi kegiatan pungutan liar. Pada aplikasi ini terdapat kelebihan yaitu masyarakat nantinya dapat memberikan bukti kegiaran pungutan liar berupa audio, gambar ataupun video.

\section{METODOLOGI PENELITIAN}

Pendekatan yang digunakan untuk pengembangan sistem dalam penelitian ini adalah prototype. Pendekatan prototype digunakan untuk mempercepat implementasi beberapa bagian dari sistem selama atau sebelum fase persyaratan. Desain prototipe, dengan cepat dievaluasi oleh pelanggan / pengguna dan hasil evaluasinya digunakan untuk memperbaiki perangkat lunak yang dikembangkan [3].

Metode pengembangan sistem yang digunakan UML. UML adalah alat untuk merinci sistem perangkat lunak yang mencakup diagram standar untuk mendefinisikan, menggambarkan dan secara visual memetakan atau memodelkan desain dan struktur sistem perangkat lunak. Diagram UML terdiri dari diagram use case, diagram kelas, diagram sekuence, diagram statechart, diagram aktivitas, diagram komponen, dan diagram deployment [4].

Metode yang dilakukan untuk membangun sistem aplikasi ini adalah sebagai berikut pada gambar 1 . Gambar 1 adalah metode pelaksanaan penelitian dari aplikasi ALPUKAT yang menggambarkan langkahlangkah pembuatan aplikasi.

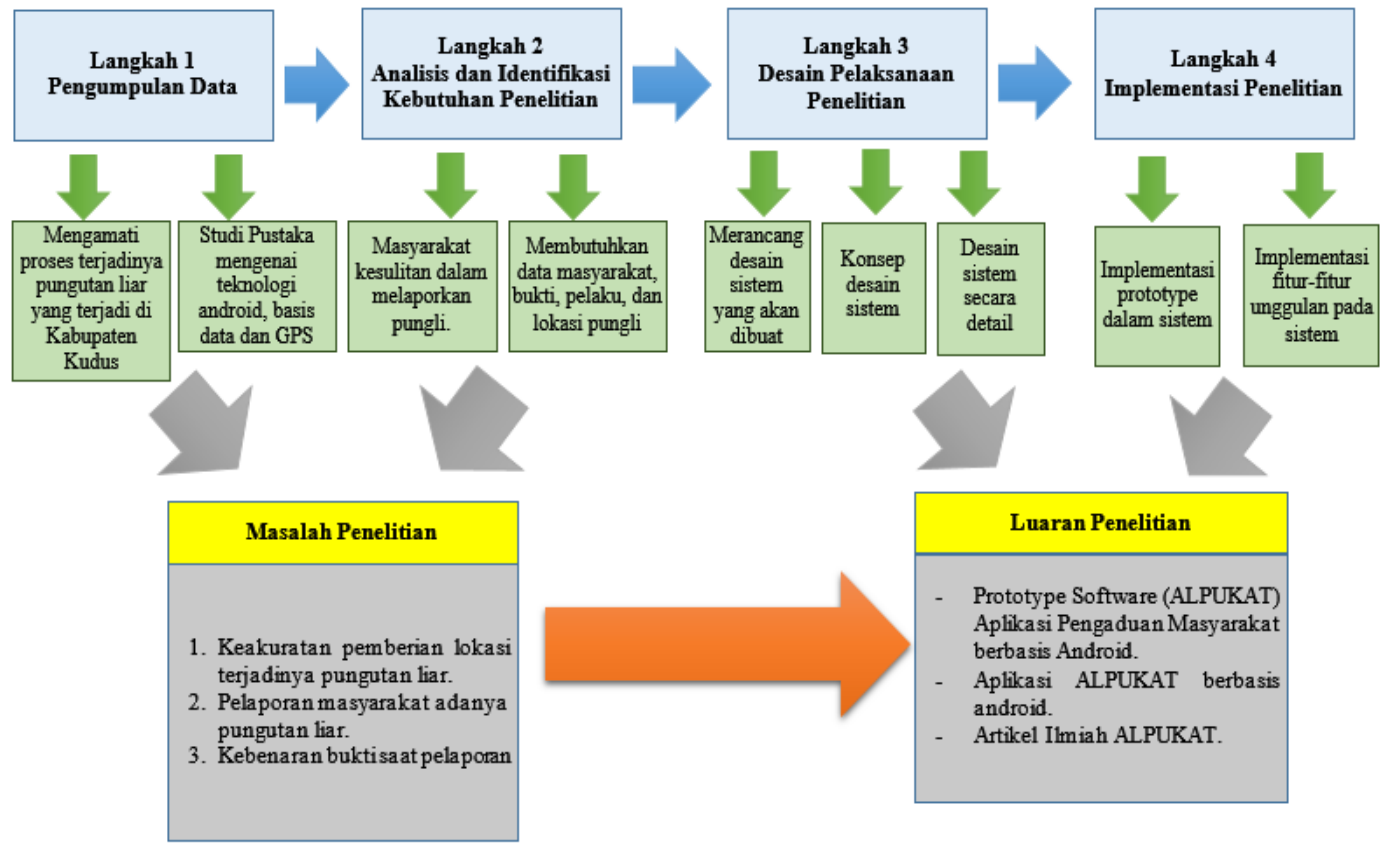

\section{Gambar 1. Metode Pelaksanaan Penelitian}

Dalam langkah pengumpulan data ini, pertama-tama melakukan pengamatan atau observasi dengan mengamati proses terjadinya pungutan liar oleh oknum yang tidak bertanggung jawab dan kami mencari referensi teknologi untuk mengetahui cara mengimplementasikan sebuah data dengan memanfaatkan teknologi basis data dan teknologi GPS dalam smartphone android untuk membuat aplikasi ALPUKAT agar dapat lebih valid dalam menyajikan informasi bagi penggunanya. 
Selanjutnya langkah kedua menganalisa solusi atas masalah yang terjadi yaitu masyarakat kesulitan dalam melakukan pelaporan kegiatan pungutan liar. Adapun sebagai data utama dalam pembuatan Aplikasi Alpukat yang diperlukan adalah data masyarakat sesuai KTP, data bukti pemungutan liar, data pelaku pemungutan liar dan data lokasi pemungutan liar.

Dalam langkah desain pelaksanaan penelitian dengan melakukan perancangan desain terhadap sistem. Memiliki beberapa urutan yaitu dengan merancang desain sistem yang akan kita buat, membuat konsep desain system, dan membuat desain sistem yang akan dibuat secara rinci.

Pada langkah implementasi penelitian akan menganaisa prototype sistem serta fitur-fitur dalam aplikasi ini. Adapun prototype dari aplikasi adalah kebutuhan hardware dan software. Kebutuhan Hardware dalam sistem terdiri dari Smartphone Android xiaomi redmi 2, Flashdisk 8 GB, 2 buah mouse. Adapun kebutuhan software dalam sistem adalah Windows 10,Andoid studio versi 2.1.2,Java Development kit (JDK),Android SDK, ADT (Android development tools). Fitur yang ada dalam sistem ini ialah dapat mengirimkan lokasi terjadinya pungutan liar dengan memanfaatkan teknologi GPS yang berada pada smartphone android, serta dapat mengirimkan buki terjadinya pungutan liar berupa audio, gambar ataupun video.

\section{HASIL DAN PEMBAHASAN}

Berdasarkan hasil pengamatan terhadap lingkungan sekitar di daerah kabupaten Kudus, diketahui bahwa masih sangat kecilnya pemahaman dan kesadaran tentang saber pungli di masyarakat. Pemerintah Indonesia juga pada akhir-akhir ini tengah gencar-gencarnya memberantas pungutan liar. Pemerintah saat ini sudah membentuk tim saber pungli berdasarkan Perpres Nomor 87/2016 tentang Satuan Tugas Sapu Bersih yang mempunyai tugas melaksanakan pemberantasan pungutan liar secara efektif dan efisien dengan mengoptimalkan pemanfaatan personil, satuan kerja, dan sarana prasarana, baik yang berada di kementerian/lembaga maupun pemerintah daerah. Pengetahuan tentang hal tersebut sangat perlu diperoleh oleh masyarakat agar terciptanya lingkungan yang aman dan adanya pungutan liar.

Sistem dari aplikasi ALPUKAT ini akan tergambar alur prosesnya melalui usecase diagram. Usecase adalah teknik untuk merekam persyaratan fungsional sebuah sistem. Use Case mendeskripsikan interaksi tipikal antara para pengguna sistem dengan sistem itu sendiri, dengan memberi sebuah narasi tentang bagaimana sistem tersebut digunakan. Use Case Diagram menampilkan aktor mana yang menggunakan Use Case mana, Use Case mana yang memasukkan use case lain dan hubungan antara aktor dan Use Case[5]. Penggambaran perancangan Use Case aplikasi ALPUKAT akan ditampilkan pada gambar 2 .

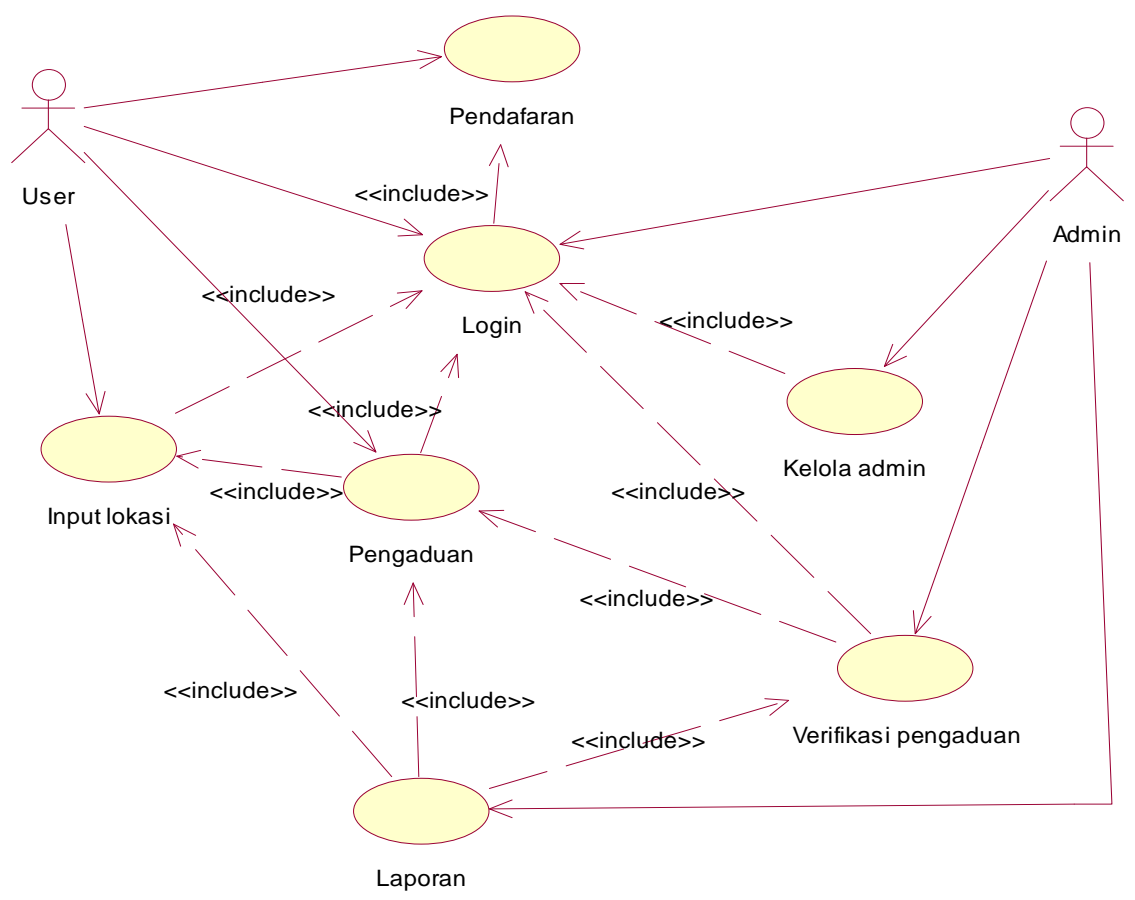

Gambar 2. Usecase Diagram Sistem 
Desain konseptual lain yang dihasilkan adalah diagram aktifitas, salah satunya yang ditunjukkan pada gambar 3. Gambar 3 menunjukkan diagram aktifitas dari aktor masyarakat saat melakukan aktifitas pendaftaran aplikasi untuk dapat melaporkan terjadinya pugtan liar di kabupaten Kudus. Diagram Aktifitas adalah tampilan grafis yang menjelaskan proses operasional dan hubungan sebab akibat yang digunakan di dalam setiap tahapan sistem [6].

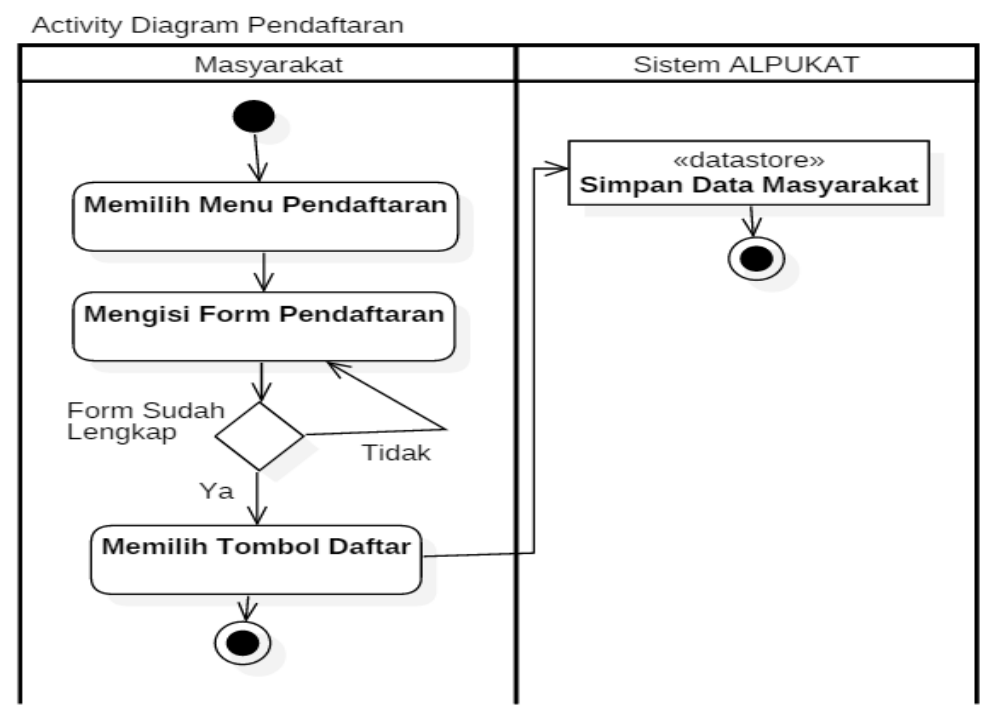

Gambar 3. Acivity Diagram Sistem Pendaftaran

Hasil tampilan antarmuka dari sistem apikasi pengaduan masyarakat tentang pungutan liar di kabupaten Kudus ditunjukkan sebagai berikut. Gambar 4 ini menunjukkan tampilan login dari aplikasi. Dalam login aplikasi terlebih dahulu mendaftarkan diri, jika sudah memiliki akun maka pengguna dapat login sistem.

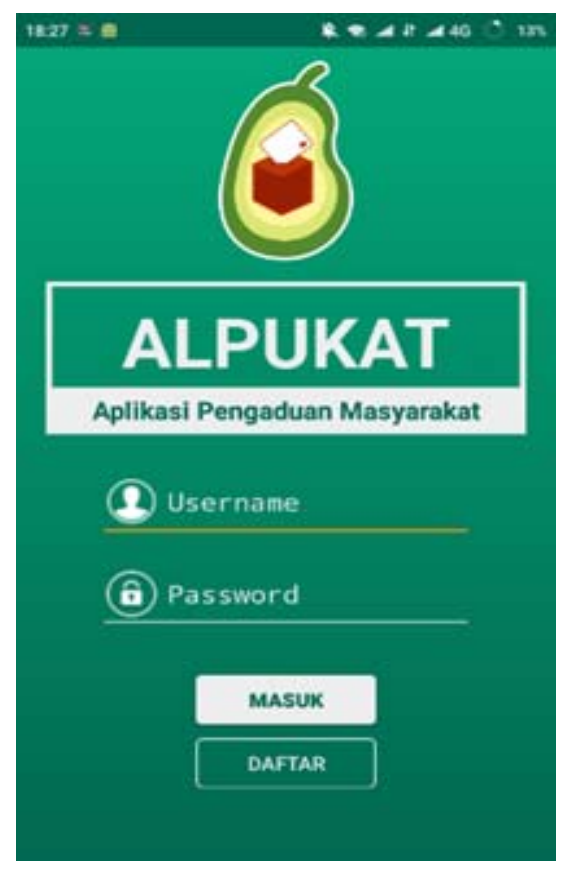

Gambar 4. Desain Login Aplikasi ALPUKAT 
Dalam gambar 5 menunjukkan fitur send lokasi untuk pengguna agar dapat mengirimkan secara langsung letak dari terjadinya pemungutan liar dengan memanfaatkan teknologi GIS (Geographic Information System).

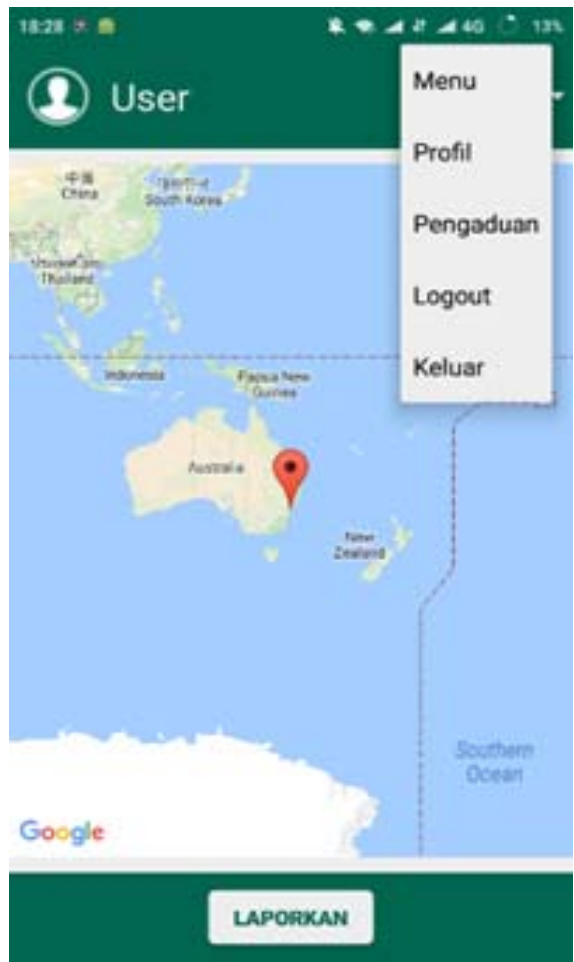

Gambar 4. Desain Send Lokasi pada Aplikasi ALPUKAT

Pada gambar 6 menunjukkan tampilan pelaporan dimana pengguna dapat melaporkan kejadian pungutan liar stelah mengirimkan lokasi kejadin. Pengguna diharuskan mengirimkan bukti dengan bentuk audio,video, atau gambar. Sedangkan tempat lokasi akan otomatis terisi setelah megirim lokasinya.

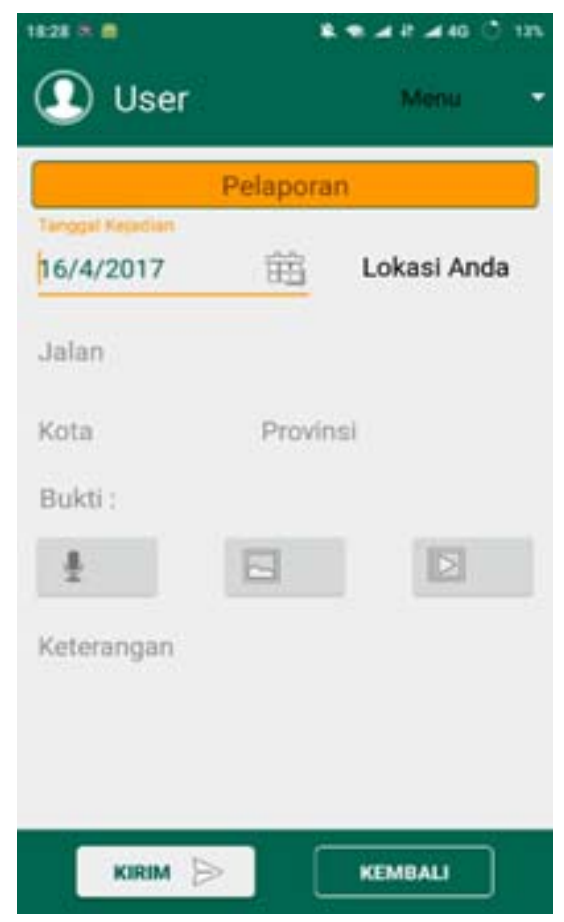

Gambar 5. Desain Pelaporan Pengaduan Masyarakat 


\section{KESIMPULAN}

Pungutan liar merupakan perbuatan yang disebut sebagai perbuatan pungli merupakan suatu gejala sosial yang telah ada di Indonesia, sejak Indonesia masih dalam masa penjajahan dan bahkan jauh sebelum itu. Maksud dan tujuan ALPUKAT untuk membuat sistem pelaporan pungutan liar berbasiskan android dengan menggunakan teknologi GPS untuk menentukan lokasi kegiatan pungutan liar. Manfaat yang diperoleh adanya sistem ini adalah masyarakat atau pengguna sistem dapat dengan mudah melaporkan kegiatan pungutan liar dengan keakuratan lokasi kegiatan pungutan liar. Pada aplikasi ini terdapat kelebihan yaitu masyarakat nantinya dapat memberikan bukti kegiatan pungutan liar berupa audio, gambar ataupun video serta keakurasian tempat terjadinya pungutan liar.

\section{UCAPAN TERIMA KASIH}

Terima kasih kepada Kementerian Riset, Teknologi, dan Pendidikan Tinggi Republik Indonesia yang telah membiayai penelitian ini melalui program kreativitas mahasiswa bidang karsa cipta.

\section{DAFTAR PUSTAKA}

[1] Peraturan Presiden. Satuan Tugas Sapu Bersih Pungutan Liar. No 87 Tahun 2016

[2] Abidin, H. (2007). Penentuan Posisi dengan GPS dan Aplikasinya. Jakarta: PT. Pradnya Pramita.

[3] Tiwari, Vinay. 2010. "Some Observations On Open Source Software Development On Software Engineering Perspectives". International Journal of Computer Science \& Information Technology (IJCSIT) 2. 6, 113-125.

[4] Lee, Sunguk. 2012. "Unified Modeling Language (UML) for Database Systems and Computer Applications". International Journal of Database Theory and Application 5. 1, 157-164.

[5] Fowler, Martin. 2005. UML Distilled Edisi 3, Yogyakarta: Andi.

[6] Mallick, Bipsha., and Das, Nilanjan. 2013. "An Approach to Extended Class Diagram Model of UML for Object Oriented Software Design". International Journal of Innovative Technology \& Adaptive Management (IJITAM) 1. 2.

[7] Kaewchinporn, Chinnapat,. and Limpiyakorn, Yachai. 2013. "Enhancement of Action Description Language for UML Activity Diagram Review", International Journal of Software Engineering and Its Applications 7. 2, 255-271 